\title{
JAVANESE SPEECH HOST IN WEDDING IN THE SIDOARJO REGION Suwito ${ }^{1}$ ${ }^{1}$ STIKES RUMAH SAKIT ANWAR MEDIKA
}

\author{
Corresponding Author: ${ }^{1}$ ahmadsuwito7@gmail.com
}

\begin{abstract}
This study describes the Javanese language used by the presenters when bringing a wedding ceremony in the Sidoarjo area. Organizers have many variations of the language used at weddings with Javanese customs. The research method uses a qualitative research method approach where this research is in the Tambak Kemerakan village area, Krian sub-district, Sidoarjo district. The time of the research was carried out from May to July 2021. The data collection techniques in the study were in the form of documents, interviews and observations. The research instrument used a mobile phone and a list of questions to the presenters. The results of the study show that the use of language includes language variations, language variations based on lecturing functions, language variations in terms of formality using official language. Code switching in this study is an analysis of the language used when hosting weddings. And the occurrence of language code mixing in the form of Javanese krama alus switching to Indonesian and language interference in its morphological and phonological use.
\end{abstract}

Key words: Language Variation, Code Switching, Code Mixing, Interference

\section{TUTURAN BAHASA JAWA PEMBAWA ACARA DALAM PERNIKAHAN DI WILAYAH SIDOARJO}

\begin{abstract}
Abstrak
Penelitian ini menjelaskan tentang bahasa jawa yang digunakan pada pembawa acara saat membawakan suatu acara pernikahan di wilayah sidoarjo. Pranataacara banyak memiliki kevariasan bahasa yang digunakan pada saat acara pernikahan dengan adat jawa. Metode penelitian menggunakan pendekatan metode penelitian kualitatif tempat penelitian ini daerah desa tambak kemerakan kecamatan krian kabupaten sidoarjo. Waktu penelitian dilaksanakan bulan mei sampai juli 2021. Teknik pengumpulan data pada penelitian berupa dokumen, wawancara dan observasi. Instrumen penelitian menggunakan handphone dan daftar pertanyaan kepada pembawa acara. Hasil penelitian menunjukan penggunaan bahasa meliputi variasi bahasa, variasi bahasa berdasarkan fungsiolek, variasi bahasa dari segi keformalan menggunakan bahasa yang resmi. Alih kode pada penelitian ini beruapa analisis bahasa yang digunakan pada saat menjadi pembawa acara pernikahan. Dan terjadinya campur kode bahasa berupa bahasa Jawa krama alus beralih ke Bahasa Indonesia dan interferensi bahasa pada penggunaanya dengan morfologis dan fonologis.
\end{abstract}

Kata kunci : Variasi Bahasa , Alih Kode, Campur Kode, Interferensi

\section{PENDAHULUAN}

Bahasa merupakan sebagai alat komunikasi yang digunakan di dalam masyrakat karena terikat tuturan-tuturan sosial. Manusia membutuhkan komunikasi dalam hal bersosialisasi kepada masyarakat oleh sebab itu tanpa adanya komunikasi berbahasa manusia akan mengalami suatu kendala dalam berinteraksi.

Di setiap kegiatan masyarakat pelaksanaan apa yang dilakukan oleh manusia sangat memperlukan suatu kerukunan dalam bahasa agar komunikasi bisa berjalan dengan baik. Semakin bertambahanya keanakeragaman dalam berbahasa yang di gunakan oleh penutur semakin banyak. Di Indonesia merupakan negara dengan masyrakat yang multikultural dan multilingual. Pada dasarnya masyrakat Indoneisa merupakan sebagai masyarakat yang mampu memakai dua bahasa yang banyak menguasai bahasa nasional yaitu Bahasa Indonesia sendiri sebagai Bahasa Ibu di negara Indonesia.

Keberdaan masyarakat Indonesia yang sangat multilingual di sebabkan adanya 
perjanjian dalam suatu bahasa. Bahasa ibu yang dipengaruhui oleh beberapa bahasa daerah yang sangat menentukan bahasa Ibu yang dimiliki di Indonesia karena bahasa Ibu merupakan sebagai dasar dalam kajian interferensi dalam kajin sosiolingusitik. di bidang sosiolingustik ada bebrapa istilah yaitu variasi bahasa, interferensi, alih kode dan campur kode.

Bahasa sering menimbulkan berbagai kontak bahasa di karenakan fenomena kebahasaan seperi terjadinya kedwibahasaan, alih kode, campur kode, interferensi bahasa dan pemertahanan bahasa menurut Chaer dan Agustian (2010: 86). Ketika masyarakat menggunakan dua bahasa yaitu bahasa ibu dan bahasa nasional dengan berbagai macam budaya yang memiliki dwibahasa. Karena banyak masyarakat Indonesia mampu memiliki dua bahasa sekaligus karena apa yag terjadi pada penelitian merupakan bahasa yang bisa dipahami dengan baik karena unsurunsurnya merupakan bagian dari suatu kajian sosiolingusitik.

Pemilihan dari sisi bahasa melibatkan berbagai keanekaragaman bahasa yang sering digunakan terjadinya proses pilihan bahasa saat berkomunikasi

\section{KAJIAN TEORI}

\section{Kajian Sosiolinguistik}

Sosiolingusitik merupakan kajian yang menyusun sebuah teori yang berdasarkan pada hubungan masyarakat pada dasarnya kajian sosiolingusitik banyak aspek yang menyakut tentang bahasa yang tejadi di masyarakat karena banyak bahasa yang berkaitan dengan ilmu-ilmu sosiolinguistik yang terjadi dimasyarakat (Nababan 1993:2)

\section{Penggunaan Bahasa}

\section{a. Variasi Bahasa}

Variasi bahasa memiliki ragam bahasa yang terletak pada konteks bahasa yang berupa variasi bahasa yang pemakainya yang berbeda-beda menurut ahli oleh Mustakim (1994:18) berbagai ragam bahasa dengan pengunaan bahasa yang berbeda-beda karena banyak topik bahasa yang berkaitan dengan tidak harus adanya penutur dan lawan tutur. Karena dalam mempertahankan bahasa masing-masing yang dilakukan antara penutur dan lawan tutur dapat mudah dimengerti dan dipahami oleh manusia.

Di banyak tempat acara pernikahan bahasa yang sering digunakan sebagai pembawa acara atau pranataacara. Berbagai variasi bahasa yang sering digunakan menjadi pranatacara berada di wilayah sidoarjo karena di wilayah sidoarjo dalam pernikahan nmenggunakan bahasa Jawa Krama Inggil.

Penelitian ini dalam pembawa acara pengantin jawa di desa Tambak Kemerakan, Kecamatan krian, Kapupaten Sidoarjo pada saat perkawinan pembawa acara mengucapkan tuturan berbahasa Jawa Krama Alus/Inggil . Karena pernikahan adalah suatu momen yang ditunggu oleh para anak-anak remaja. Dalam ikatan pernikahan budaya Jawa merupakan suatu tradisi adat jawa yang selalu di hubungkan dengan suatu nilai sakral karena pernikahan merupakan suatu dua insan yang direstu oleh agama, hukum dan masyarakat.

Penelitian ini tentang Tuturan Bahasa jawa pada Pembawa acara dipernikahan di desa Tambak Kemerakan, Kecamatan Krian Kabupaten Sidoarjo

pembicaraan. Dari penjelasan bahwa ragam bahasa yang banyak varisivariasi bahasa yang memiliki pola umum dari bahasa yang dimiliki oleh masyarakat. Pada dasarnya variasi bahasa mempunyai perbedaan latar belakang yang berbeda yaitu sosial, agama, budaya dan perbedaan lainnya. Banyak media yang digunakan mempengaruhui terjadinya ragam bahasa atau variasi bahasa. Ketika terjadi interaksi pada masyarakat yang berbeda ragam bahasa mengakibatkan terjadinya variasi bahasa yang dikemukakan oleh Chaer dan Agustina (2010:62) banyak terjadi pembeda dalam variasi bahasa yaitu variasi bahasa dari segi sarana, keformalan dan segi penutur. Akan dijelaslan tentang variasi bahasa sebagai berikut:

1. Variasi Bahasa dari sisi penutur 
Variasi bahasa yang mempunyai sifat individual karena bersifat relatif dalam variasi bahasa dari segi penutur diantaranya yaitu dialek, idiolek, sosiolek.

2. Variasi Bahasa dari segi pengguna Variasi bahasa dari segi pengguna apa yang dijelaskan oleh Nababan (dalam chaer dan Agustina 2010:68) karena variasi bahasa yang berkiatan dengan penutur yang disebut juga sebagai fungsiolek sebagai ciri variasi bahasa yang menyakut bahasa yang digunakan sebagaimana pada tempatnya bahasa yang diperlukan contohnya pada bidang wartawan atau jurnalistik, pendidikan dan sosial apa yang menjadi contoh tersebut berbagai bidang merupakan varisi bahasa yang menonjol yang berupa kosakata bahasa yang digunakan penutur bahasa.

3. Variasi bahasa dari segi Tempatnya Variasi bahasa ini merupakan ragam bahasa yang berdasarkan tempat atau sarana yang sering digunakan dalam pembicaran bahasa. Hal ini ada dua ragam bahasa yang bisa dijelaskan secara tertulis dan lisan. Ada berapa faktor mendukung variasi dari sisi sarana atau tempat berupa variasi suprasegmental yang berupa suara yang ditekan miliki getaran yang dapat melihatkan emosi dari sisi penutur.

4. Variasi bahasa dari Segi Keformalan Variasi bahasa dari segi keformalan ada beberapa macam variasi bahasa yang bisa dijelaskan dari pendapat ahli Chaer (2010:70) ada lima macam gaya variasi bahasa yang merupakan bagaian dari ragam bahasa baku yang tidak sama dengan bahasa santai ketika bertemu dengan saudara dan teman.

a. Ragam baku adalah suatu ragam resmi yang digunakan pada situasi dan kondisi pada varisai bahasa yang formal sangat baik, dan banyak kegiatan upacara kenegaran dengan menggunakan bahasa yang resmi dan ketika pengampilan sumpah para pejabat.

b. Ragam resmi (formal) pada dasarnya jenis ragam yang resmi banyak memiliki kesamaan dengan ragam baku dalam penjelasanya berbagai ahli ragam resmi bisa menggunakan yang diajak berkomunikasi dengan menentukan bahasa yang resmi atau tidaknya suatau bahasa ragam formal atau resmi.

c. Ragam usaha (Konsultatif) adalah ragam usaha dengan berbagai komunikasi ketika sekolah yang sangat berkaitan dengan hasil produksi pada saat menjalankan dagangnya karena dalam penggunaan ragam usaha misalnya pembicaran di pasar antara penjual dan pembeli di sebut dengan ragam usaha.

d. Ragam santai (casual) adalah Ragam bahasa pada saat pembicaran ketika berada dimana saja bertemu dengan keluraga, sahabat dan tetangga karena dari pembicaraan tersebut merupakan ragam santai yang bisa diterima dengan baik bebas dalam berbicara dan bertutur kata

\section{Alih Kode}

Alih Kode bagian dari peristiwa disebabkan terjadinya adanya peralihan kode yang satu ke kode yang lain karena adanya perpindahan bahasa jawa ke bahasa Indonesia maka akan terjadinya sebuah alih kode bahasa yang terjadi ketika pembawa acara menggunakan bahasa jawa krama alus lalu bisa berpindah bahasa ke bahasa Indonesia atau bisa kebahasa Arab. Menurut pendapat suwito (1993:68) alih kode menurut berapa ahli merupakan suatu aspek yang saling terjadi pada masyarakat pada umumnya yaitu sebagai masyarakat multilingual yang hampir tidak mungkin 
karena penutur yang menggunakan bahasa yang resmi tanpa sedikit menggunakan bahasa tanpa memanfaatkan bahasa atau unsur bahasa yang lain. Dari berbagai pendapat yang sudah dijelaskan di atas adanya perlalihan bahasa ke bahasa satunya yang disebabkan adanya penutur yang menyesuaikan suatu keadaan dimana penutur harus ber alih kode.

\section{Campur Kode}

Campur kode adalah keadaan berbahasa lain ketika orang mencampur dua atau lebih karena bahasa dan ragam suatu tindak bahasa (Speech Act Atau Discourse) tanpa sesuatu dalam berbahasa yang menuntut percampuran bahasa (Nababan: 1991:32). Menurut pendapat lain ditegaskan oleh suwito (1983:75) campur kode suatu ragam bahasa yang memiliki ketergantungan adanya hubungan timbal balik kepada penutur dan mitra tutur. Pada dasarnya campur kode merupakan bahasa campuran yang akan mempermudah penutur ketika berinteraksi kepada lawan tutur yang sama-sama memahami bahasa yang diucapkan oleh penutur.

\section{Interferensi}

Menurut para pendapat interferensi dijelaskan oleh Weinreich (dalam Chaer, 2010:122) Interferensi bagain dari bidang bahasa yang meliputu tentang fonologi dan morfologi dan sistem lainnya. Karena interferensi bagian dari sistem bahasa yang digunakan secara sistematik. Ada pendapat ahli yang mengemukan oleh Suwito ( 1983;54) interferensi sangat mempengaruhui perubahan dalam perananan sebagai ragam bahasa. Dari berbagai pendapat ahli dapat disimpulkan interferensi merupakan tuturan bahasa ketika berbicaraa dan menulis. Adanya proses yang terjadinya interferensi di maknai menjadi pengguna bahasa yang mengalami proses yang sangat mempengaruhui bahasa lain. Karena interferensi sangat tidak terbatas terjadi percampuran bahasa dari bahasa pertama ke bahasa kedua karena dapat menimbulkan sebuah interferensi Ada berapa macam tentang interferensi menurut pendapat ahli Chaer dan Agustina (2010:122) interferensi bisa dibagi menjadi empat bagian yang pertama Interferensi pada bahasa fonologi dengan penutur membicarakan kata-kata dari suatu bahasa yang menyisipkan berbagai bunyi bahasa dari bahasa lain, yang kedua merupakan interferensi morfologis yang mempunyai kata yang berafiks, ketiga interferensi adanya sintaksis yang berstruktur dengan bahasa lain di gunakan pada pembentukan kalimat.

\section{Acara Perkawinan}

Dalam ikatan cainta antara laki dan perumpan ketika menjalin kasih untuk kelurga merupakan dari sebuah perkawanian. Karena perkawinan momen yang sangat penting bagi para laki-dan perempuan ketika mau menjalankan sebuah ikatan cinta yaitu perkawaninan seumur hidup yang mempersatukan kedua keluarga. Menurut pendapat Khazim (2006: 28) pernikahan menjadikan sebuah aturan sosial yang memiliki kelanjutanya secara terus menerus dalam mematuhui aturan sosial yang berlaku karena tujuan dari perkawaninan mempunyai tanggung jawab kepada orang yang sudah dewasa. Berdasarkan penjelasan di atas bahwa perwakinan mempunyai hubungan yang erat dalam menyatukan satu kelurga menjadi keluraga yang besar. Dengan adanya pernikahan bisa menyatukan ketidaksamaan dalam keluarga baru. Karena banyak faktor yang mempengaruhui hubungan anatara suami dan istri yang menjadi baru menjadi kelurga.

\section{Pembaca acara pernikahan}

Pembawa acara atau pranatacara suatu profesi yang sangat dihormari para masyarakat dan sangat bernilai baik karena mempunyai peran sangat penting bagi yang mempunyai acara agar acara berjalan dengan lancar agar penonton menyukai apa yang sampaikan oleh pembawa acara atau pranataacara. 
menurut

Budyasusastra

(2015:23)pranatacara seorang yang memiliki tugas dan peran dalam mensuseskan sebuah acara dari pembukaan, acara inti, hiburan dan

\section{METODE PENELITIAN}

Penelitian ini pada dasarnya mendeskripsikan sebuah fenomena, peristiwa dan aktivitas soal sebagai pemikiran orang secara individu maupun kelompok. Metode penelitian merupakan sebuah teknik atau cari mencari, memperoleh, mengumpulkan atau mencatat data. Menurut David Wiliams (dalam moleong, 2007) menggunakan metode deskriptif kualitatif karena pada dasarnya penelitian ini bersifat dekriptif, pengumpulan data digunakan metode alamiah, dilakukan peneliti yang mempunyai perhatian alamiah.

Pada dasarnya penelitian ini adalah pengamatan terhadap objek tempat yang sangat penting pada sebuah acara pernikahan adat jawa di tempat Sidoarjo. Pembawa acara di sebuah acara pengantin yang berbicara bahasa Jawa Krama inggil memandu sebuah acara agara acara pengantin berjalan dengan lancar. Syarat sebagai seoarang pembaca acara mempu menciptakan suasana akrab, meriah bertanggung jawab atas lancarnya acara dan mempunyai bahasa yang komunikatif, mempunyai wawasan yang luas agar tema pembicaraan kepada audies bisa diterima dengan baik dan nenjadi pembawa acara yang homuris, kreatif dan memiliki penguasaan bahasa yang baik dan benar.

Penelitian tentang pranataacra pada acara pengantin Jawa berada di Desa Tambak Kemeraken, Kecamatan Krian Kabupaten Sidoarjo pada tanggal 24 Juli 2021. Peniliti terlibat di sebuah acara pengantin Jawa peneliti terlibat lansung pada acara tersebut sebagai merekam ketika pembawa acara membuka acara samapi acara penutup. Untuk analisis data pada penelitian dengan berbagai macam analisis Interaktif menurut ahli Sutuyo (2002:94) dilaksanakan pada dua tahap pertama saat ketika selama berlangsung sebuah acara di pandu pembawa acara. Secara lebih jelasnya pada analisis data mereduksi data, penyajian data dan penarikan kesimpulan.

Menurut Sugiyono (2015:249) Reduksi data sebuah pemikiran yang sesitif yang penutup. Dapat disimpulkan dari penjelasan di atas seorang pembawa acara merupakan sebagai pemandu acara agar acara berjalan dengan lancar dan teratur.

memerlukan kecerdesan dan keluasaan dan kedalaman wawasan yang baik. Karena peneliti bisa melakukan reduksi data dapat mendiskusikan pada teman arau orang lain. Mereduksi data yang dilakukan oleh peneliti karena penelitian memiliki pola yang harus diperhartika dalam melakukan reduksi data.

\section{HASIL DAN PEMBAHASAAN}

\section{a. Variasi Bahasa}

Variasi bahasa dalam acara pernikahan adat jawa yang menggunakan bahasa Jawa Krama Alus karena pada dasarnya bahasa Jawa Ngoko merupakan sebagai percampuran dengan Bahasa Indonesia bahasa yang digunakan pada acara pengantin menggunakan bahasa Jawa Krama Alus. Dari penjelasan di atas seperti contoh data sebagai berikut:

"Winantu saguingin karahayan saha lumintung budi satuhu mugya tansah kajiwa lan kasarira dumateng panjenangan sedaya. Dhumateng poro alim Ulama ingkang rinten dalu tansah sumanding kitab suci. Wahyungin Ilahi minangka panuntun kiblating panembah ingkang satuhu luhure budi"

Pada data tersebut bisa dijelaskan ada berapa perolehan variasi bahasa karena contoh di atas merupakan bahasa pembuka bagi pranataacara karena bahasa tersebut lebih dominan menggunakan bahasa Jawa Krama Alus/Inggil. Dikarenakan sebagai pembawa acara pengantin jawa bisa dipahami oleh masyarakat sekitar. Karena masyarakat tersebut kebayakan orang jawa dari lahir. Dari kalimat tersebut pembawa acara memberikan menjelaskan tentang menghormati kepada ulama yang selalu memberikan doa kepada para pengantin akar acara tersbut berjalan dengan lancar, karena ulama yang memberikan pengajaran kepada masyarakat lebih baik lagi. 


\begin{abstract}
"Para Pengemban Pangembating praja miwah pangarsaning nagari ingka minangka pandam pandoming kawula dasih ingkang sinobo ing pangurmatan. Para purna karya labet praja ingkang mahabeg luhure darma. Miwah para kadang sutrisna mudha wredha ingkang pantes sinudharsana.

Pada data diatas dapat dijelaskan ada berapa variasi bahasa yang mempunyai arti tentang penghormatan kepada pejabat desa,para orang tua dan para pemuda sekitar yang ikut membantu acara pernikahan adat jawa. Data tersebut selalu digunakan ketika sebagai pembawa acara atau pratacara untuk menyambut dan memberikan hormat kepada semua undangan yang datang pada acara pernikahan.
\end{abstract}

\section{b. Alih Kode}

Alih kode pada pembawa acara atau pranataacara menggunakan bahasa Indonesia beralih ke bahasa Jawa Krama alus /Inggil karena pranataacara pada acara pernikahan budaya jawa tidak selalu berbicara Bahasa jawa tapi ada beberapa situasi dalam acara menggunakan bahasa Indonesia. Pada penjelasan di atas ada beberapa data yang beralih kode dengan perpindahan bahasa sebagai berikut:

" Katuring pinarak lenggah poro tamu undangan. Hadirin para tamu dimohon untuk duduk kembali"

Pada data diatas adalah contoh alih kode yang menjelaskan bahwa sebuah acara menggunakan bahasa Jawa Inggil tetapi dapat menyisihkan kalimat Bahasa Indonesia agar undangan yang hadir juga bisa memahami apa yang di ucapkan oleh pembawa acara data tersebut peralihan bahasa Jawa ke bahasa Indonesia dikarenakan terdapat alih kode eksternal.

\footnotetext{
"Para tamu undangan kakung soho putri ingkang lenggah, katuraken jumengan sawatawis, kunjuk bapak, ibu ingkang lenggah kula dheraken jumengan. Hadirin para tamu undangan dipersilahkan untuk berdiri sejenak untuk mempelai berdua yang akan melaksanakan upacara adat"
}

Data yang dijelaskan di atas merupakan data yang menjelaskan tentang peran alih kode karena pada dasarnya yang digunakan bahasa Jawa Krama Alus/Inggil dapat beralih ke Bahasa Indonesia. Tujuan dari pembawa acara atau Prataacara untuk memberikan penjelaskan kepada tamu undangan untuk berdiri sejenak dengan bahasa Jawa alus dan diberikan penegasan menggunakan berbahasa Indonesia agar lebih dimengerti sama masyarakat sekitar.

\section{c. Campur Kode}

Campur kode pada saat pembawa acara di pernikahan budaya jawa bertujuan mendiskripiskan sebagai bentuk tuturan bahasa yang di bawakan pembawa acara dalam memandu acara pernikahan. Ada beberapa contoh tentang campur kode dalam pembawaa prataacara sebagai berikut:

"Nggenipun bapak tohir Ibu Menik sakeng dari sidoarjo Keparang Pengantin, Kakung Bagus jahari enggal kebayang wonten Ing sasono"

Pada data di atas dapat dijelaskan bahwa campur kode yang dijelaskan data yang disisipkan dengan Bahasa Indonesia kalimat Pengantin seharusnya menggunakan bahasa Jawa adalah penganten . contoh di atas merupakan campur kode dalam penggunaan bahasa jawa krama alus beralih dengan menggunakan bahasa Indonesia. Hal di jelaskan pada saat acara pengantin laki-laki duduk diperlaminan. Sedangkan sebagai pembawa acara menyebutkan mempelai pria segera datang menuju tempat singasana. Bisa disimpulkan dari penjelasan tersebut adanya campur kode yang di ucapakan oleh pembawa acara karena awalnya menggunakan bahasa Jawa Krama Alus/Inggil beralih ke bahasa Indonesia..

"Mbokbilih temanten putri dyah ayu larasati Nggen Hang Luhur Saliro sampun paripurno, Keparengipun miyos saking sasono ngarep inggih mekaten kunjuk Bopo suparno miwah Ibu sri wahyuni kepareng saget jengkar saking sasono"

Pada kalimat di atas tersebut dijelaskan bahwa campur kode yang didapat dengan penyisipan data yang ditunjukan data terdapat pada kata : 
Kata "Ngarep" merupakan bahasa Jawa krama ngoko seharusnya bahasa yang disampaikan dengan menggunakan bahasa Jawa Alus yaitu dengan bahasa "Ngajeng". Data tersebut menjelsakan kepada undangan bahwa pengantin putri duduk di singasana dan di harapkan kepada orang tua atas nama bapak suparno dan ibu Sri Wahyuni menuju tempat yang sudah disediakan. Jadi dapat disimpulkan bahwa pembawa acara menggunakan bahasa jawa ngoko bercampur dengan bahasa Jawa Alus.

\section{Interferensi}

Bahasa Interferensi dalam pembawa acara di pernikahan budaya jawa memberikan penjelasan untuk mendiskripsikan bentuk bahasa yang dibawakan oleh pembawa acara dalam memandu acara pernikahan jawa. Pembawa acara di perkawinan budaya jawa ada beberapa contoh data yang menunjukan Interferensi sebagai berikut:

" Bopo Trisno miwah kerso dherek mantui dhateng panjengan bopo jahari miwah Ibu Sri Wahyuni."

Data tersebut menjelaskan merupakan data dari interferensi di sebabkan adanya interferensi suatu bahasa pada bidang morfologi karena ada imbuhan huruf " $I$ " di akhir kata mantui yang sesuai data yang sudah ada contoh sebagai berikut.

"Bopo Jari miwah Ibu Pon Kersi dherek Mantui dhateng nggenipun Bopo salken miwah ibu sri ningsih".

Pada data diatas merupakan contoh data interferensi pada contoh kata Mantui diakrenakan adanya sebuah interferensi pada bidang morfologis dikarenakan ada penambahan huruf "I" di akhiri kata Mantui . Dari data di atas terjadinya adanya interferensi morfologis diakrenakan penggunan bahasa Jawa Krama Alus/Inggil dipengaruhui bahasa Jawa Ngoko.

" Bapak, Ibu Ingkang dahad kinurmantan, Teng mriki sakderingipun putro temanten menghadap kasuwun poro tamu kakung soho putri ingkang lenggah katuran jumeneng sakwetawis"

Pada data di atas dijelaskan contoh dari sebuah interferensi bahasa pada data "Teng" disebabkan adanya perubahan interferensi bahasa di bidang fonologi perubahan bunyi dikarenakan ada huruf yang hilang yaitu kata "Dha" seharunya kata tersebut yang tepat yaitu "Dhateng" dari data tersebut adanya interferensi fonologis dikarenakan penggunaan bahasa Jawa Krama Inggil dipengaruhui bahasa Jawa Ngoko. Berdasarkan data yang dijelaskan para tamu undangan untuk menikmati acara pernikahan karena acara temu manten adat jawa belum selesai acaranya untuk itu pembawa acara memberikan penjelasakan kepada tamu undangan dan keluarga agar bisa memahami acara pernikahan adat jawa berlangsung.

\section{SIMPULAN}

Berdasarkan kesimpulan dari penelitian ini penggunan tuturan bahasa pada pembawa acara pengantin jawa di desa desa tambak kemerakan, Sidoarjo sebagai berikut:.

1. Dari hasil penelitian pada variasi bahasa ada tiga macam variasi bahasa ditemukan bahasa yang pertama variasi bahasa dari segi tuturan yang berupa lambang karena banyak bahasa-bahasa pada saat membawakan sebauah acara pengantin Jawa menyampaikan dengan menggunakan bahasa Jawa Ngoko Alus. Kedua variasi bahasa yang dari sisi pemakain bahasa terdiri dari fungsiolek dengan penggunaan tuturan bahasa Jawa Krama Alus yang biasanya lebih dominan ketika saat menjadi pembawa acara dalam menyampaikan bahasa jawa dalam acara pernikahan. Sedangkan yang ketiga variasi bahasa dari dari penggunaan bahasa yaitu keformalan yang bersifat resmi pada suatu acara di pemerintahan dengan menggunakan bahasa yang resmi dan baku. Dapat disimpuilkan terjadinya variasi bahasa adanya tuturan saling berinterkasi dengan berbagai macam varisai bahasa yang diperoleh..

2. Data Alih Kode pada penelitian ini disebabkan adanya perlalihan tuturan Bahasa Jawa ke Bahasa Indonesia ketika memberikan penjelasan kepada para undangan atau pengantin. Pembawa acara melakukan alih kode karena menyesuikan kondisi dilapangan ketika pada saat acara manten di mulai. Karena bahasa Indonesia mudah dipahami dan menjadi bahasa nasional.

3. Data Campur kode yang dihasilkan pada penelitian merupakan sebagai pembawa acara dalam membawakan acara dengan berbagai campuran bahasa seperti penggunaan tuturan bahasa jawa ngoko ke 


\section{Jurnal DISASTRI (Pendidikan Bahasa dan Sastra Indonesia) \\ Volume 3, Nomor 2, Agustus 2021| P-ISSN : 2716-4114 | E-ISSN: 2722-3329}

bahasa Jawa Krama Alus lalu ke bahasa Indonesia karena pembawa acara bisa menyesuaikan tamu undangan apa yang dibicarakan semua bisa dipahami dari berbagai kalangan dengan yang tua dan yang lebih muda. Jadi sebagai pranataacara harus bisa melihat konsidi yang dilapangan ketika akan memulai sebagai pembawa acara.

4. Data Interferensi pada penelitian di atas terdapat dua data interferensi yaitu data morfologis dan fonologis yang mempengaruhui bunyi sebuah tuturan. Ada beberapa kosakata yang hilang pada suatu huruf kata karena adanya pengaruh bahasa jawa ke bahasa Indonesia. Dapat disimpulkan dari dua interferensi sangat mempengaruhi sebuah tuturan pembawa acara ketika berada di tempat ini akan menjad suatu pembahasan yang bagus karena bisa di mengerti adanya perubahan bahasa Jawa Ngoko ke Bahasa Jawa Alus atau mungkin bisa ke Bahasa Indonesia.

\section{DAFTAR PUSTAKA}

Aslinda dan Syafyahya. 2010. Pengantar Sosiolingusitik. Bandung: Refika Aditama.

Budyasastra, Ki Puspa. 2015. Panduan Lengkap Menjadi MC Profesioanal dan Ahli Pidato Bahasa Jawa Pranatacara lan Sesorah. Yogyakarta: Araksa.

Chaer, Abdul dan Agustina Lenonie. 2010. Sosiolinguistik. Perkenalan Awal. Jakarta: Rineka Cipta.

Endraswara, Suwardi. 2009. Mutiara Wicara Jawa. Yogyakarta: Gadjah Mada University Press.

Fatimah, Fauziah Nurul,dkk.2018. Analisis kesalahan berbahasa pada pembawa acara.Jurnal parole. (online) https://journal.ikipsiliwangi.ac.id/index .php/parole/article/view/1127) diakses pada tanggal 26 Juli 2021

Kazhim, Muhammad Nabil. 2009. Panduan Pernikahan Ideal. Bandung: Irsyad Baitus Salam.

Moleong, J. Lexy. 2007. Metodologi Penelitian Kualitatif. Bandung: PT. Remaja Rosdakarya.

Nababan, P.W.J. 1991. Sosiolinguistik Suatu Pengantar. Jakarta: Pustaka Utama.
Rokhman, Fathur. 2013. Sosiolinguistik Suatu Pendekatan Pembelajaran Bahasa dalam Masyarakat Multikultural. Yogyakarta: Graha Ilmu.

Sutopo, H.B. 2002. Metodologi Penelitian Kualitatif Teori dan Terapannya dalam Penelitian. Surakarta: Sebelas Maret University Press.

Suwito. 1983. Pengantar Awal Sosiolinguistik Teori dan Problema. Surakarta: Hennary Offset Solo.

Ula, Mardiyatul, dkk.2020. Penggunaan Bahasa Pembawa AcaraI. Jurnal Widyabastra (Online) $\underline{\text { http://e- }}$ journal.unipma.ac.id/index.php/widya bastra/article/view/6765 ) diakses pada tanggal 26 Juli 2021 
Jurnal DISASTRI (Pendidikan Bahasa dan Sastra Indonesia)

Volume 3, Nomor 2, Agustus 2021| P-ISSN : 2716-4114 | E-ISSN: 2722-3329 